\title{
A Measurement of the Velocity of Propagation of Very-High-Frequency Radio Waves at the Surface of the Earth
}

\author{
Edwin F. Florman
}

\begin{abstract}
The velocity of propagation of electromagnetic waves was measured at the surface of the earth, using a radio-wave interferometer operating at a frequency of $172.8 \mathrm{Mc}$. The measured phase velocity, converted to velocity in vacuum, or the "free-space" value, was found to be $299795.1 \pm 3.1 \mathrm{~km} / \mathrm{sec}$. The uncertainty of $\pm 3.1 \mathrm{~km} / \mathrm{sec}$ includes a 95 -percent confidence interval for the mean, plus an estimated limit to the systematic error of \pm 0.7 $\mathrm{km} / \mathrm{sec}$. Based on a 50-percent confidence interval (probable error of the mean), the uncertainty, including the estimated limit to the systematic error of $\pm 0.7 \mathrm{~km} / \mathrm{sec}$, becomes $\pm 1.4 \mathrm{~km} / \mathrm{sec}$.

The accuracy with which the free-space phase velocity of radio waves could be measured was limited primarily by the accuracy to which the refractive index of air could be obtained from measured values of pressure, temperature, and relative humidity.
\end{abstract}

\section{Introduction}

Measurements of the velocity of propagation of electromagnetic waves have been carried out by a large number of investigators over a long period of

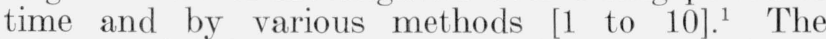
primary object of their work has been to obtain an accurate value of the "free-space" velocity of electromagnetic waves for use both in theoretical and practical applications of this fundamental constant.

From a study of various methods that could be used to measure the velocity of propagation of radio waves, it was concluded that the radio-wave interferometer principle could be applied to yield fieldtest results having a high order of accuracy. A VHF radio wave $(172.8 \mathrm{Mc})$ was used in carrying out the phase-velocity measurements covered by this report in order to avoid sky-wave interference, minimize ground effects, and reduce the physical size of the measuring system to dimensions that were convenient for standard distance-survey techniques.

\section{Theory and Operational Technique}

Determination of the phase velocity of radio waves described in this report was dependent upon the measurement of:

(a) the linear distance, $S$, between two (radiosignal) receiving points,

(b) the frequency, $f$, of the radio transmission,

(c) the net change in phase, $\Phi$, of the signals at the two receiving points when the radio transmitter was moved over a prescribed course, and

(d) the average wave index of refraction of the air, $n$.

The free-space phase velocity, $V$, of the radio waves in terms of the phase velocity between the

\footnotetext{
1 Figures in brackets indicate the literature references at the end of this paper.
}

two receiving points at the surface of the earth is given by

$$
V=f \lambda n=f \frac{S}{\Phi} n
$$

where $\lambda$ is the wavelength of the radio waves at the earth's surface.

If the source of the radio-wave transmission is more than several hundred wavelengths distant from the receiving points, the effect of the earth's surface on the velocity of propagation of radio waves is small and can be calculated [16]; furthermore, "induction field" effects [21] are negligible under these conditions.

The basic elements of the system used to carry out the phase-velocity measurements are shown in figure 1. $R_{1}$ and $R_{2}$ are two receiving points, $S$ is the accurately surveyed distance from $R_{1}$ to $R_{2}$, and $T_{1}$ and $T_{2}$ are radio transmitters located on the extensions of the straight line through the receivers.

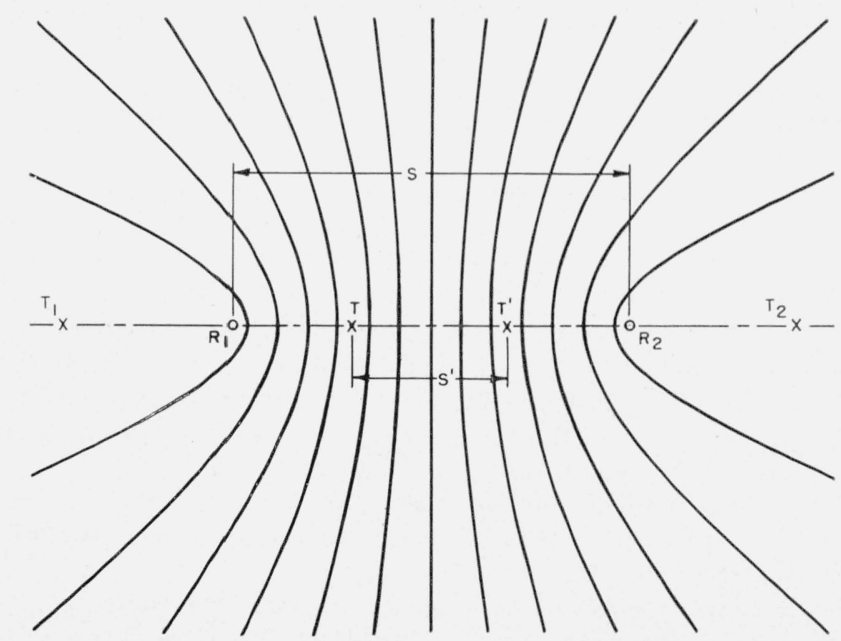

Figure 1. Phase field in the vicinity of two radio receivers. 
The family of hyperbolic curves are equiphase contours in the horizontal plane through $R_{1}$ and $R_{2}$, with these receiving points as foci. In other words, if a radio transmitter is moved along any one of these hyperbolas, the change in phase difference between signals at the receiving points is zero. In the regions of the receiver-line extensions, the hypervolic contours degenerate to the straight lines $R_{1}-T_{1}$ and $R_{2}-T_{2}$.

Referring to figure 1, if a radio transmitter is moved from $T$ to $T^{\prime}$, on the receiver line, the phase of the signal will be retarded at $R_{1}$ and advanced at $R_{2}$. Designating the change in phase difference as $2 \Phi^{\prime}$, it is evident that the value of $\lambda$ in eq (1) is

$$
\lambda=\frac{S^{\prime}}{\Phi^{\prime}} \text {. }
$$

Practical considerations show that the accuracy of the measurement of $\lambda$ can be improved by increasing the length of the path $S^{\prime}$. The limiting case occurs when $S^{\prime}$ equals $S$, but it is not feasible to move the radio transmitter from $R_{1}$ to $R_{2}$ because of radioreceiver overloading and near-zone effects $[10,11,12$, $13,21]$ that occur when the radio transmitter is in the vicinity of the receiving points. A study of the equiphase contours in figure 1 shows that moving the radio transmitter from $T_{1}$ to $T_{2}$, along a path that avoids points $R_{1}$ and $R_{2}$ by several hundred wavelengths, is equivalent to moving the transmitter from $R_{1}$ to $R_{2}$, except that in the former case, receiver overloading and near-zone effects are avoided. The net change in phase, $2 \Phi$, which occurs at $R_{1}$ and $R_{\varepsilon}$ as the radio transmitter is moved from $T_{1}$ to $T_{2}$, together with the measured distance $S$, give a value of $\lambda$ when substituted in eq (1a).

It should be noted that the path traversed by the radio transmitter must begin on one extension of the receiver line and must end on the other extension of this line.

In order to avoid transporting the radio transmitter around the system, we can use two radio transmitters (of the same frequency) located at the ends of the above path and obtain a measure of $\Phi$ by noting the change in phase at the two receiving points when transmission is switched from one radio transmitter to the other. The ambiguity of this measurement can be resolved by making one (preliminary) trip with a radio transmitter halfway around the system and noting the number of whole wavelength changes in phase that occur between the signals at the receiving points.

Furthermore, it is convenient to make the actual phase measurement at an audiofrequency rather than at a radio frequency. This audiofrequency signal can be obtained by heterodyning the radio-frequency signal with another radio-frequency signal differing in frequency by an audiofrequency rate. The phase changes between the resulting audiosignals at the receiving points is the same as the phase changes between the original radio-frequency signals, as explained below.

The phase relationships of the various signals at the receiving points $R_{1}$ and $R_{2}$ can be determined from the following considerations. With radio transmissions from $T_{0}$ and $T_{1}$, assuming that the frequency of $T_{0}$ is lower than the frequency of $T_{1}$, the vector relationship of the signals at $R_{1}$ and $R_{2}$ will be as shown in figure 2 . In this figure the heterodynefrequency phase is shown as the angle $\Phi_{1}$, and is equal to the number of degrees by which the phase of the heterodyne-frequency signal at $R_{1}$ leads the heterodyne-frequency signal at $R_{2}$. Likewise, in figure 3 , when $T_{0}$ and $T_{2}$ are transmitting with the

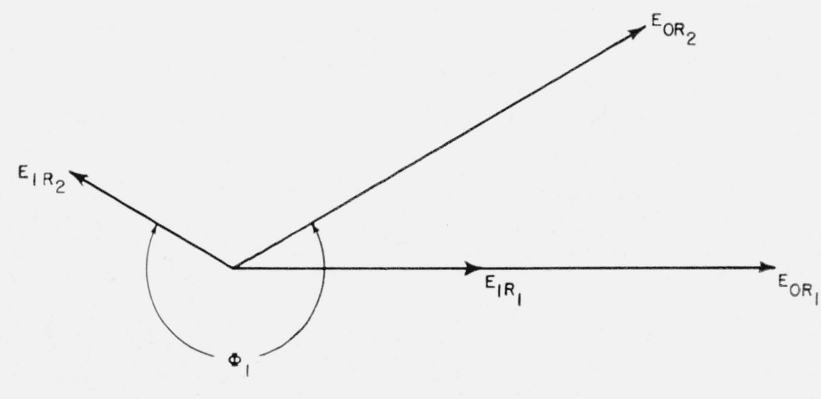

$$
\begin{aligned}
& E_{O R_{1}}=\text { VOLTAGE AT } R_{1} \text { DUE TO TRANSMISSION FROM TO } \\
& E_{O R_{2}}=\text { VOLTAGE AT } R_{2} \text { DUE TO TRANSMISSION FROM TO } \\
& E_{I R_{1}}=\text { VOLTAGE AT R DUE TO TRANSMISSION FROM } T_{1} \\
& E_{1 R_{2}}=\text { VOLTAGE AT } R_{2} \text { DUE TO TRANSMISSION FROM T }
\end{aligned}
$$

FiguRE 2. Vector relationship of voltages at receiving points $R_{1}$ and $R_{2}$ with transmissions from $T_{0}$ and $T_{1}$.

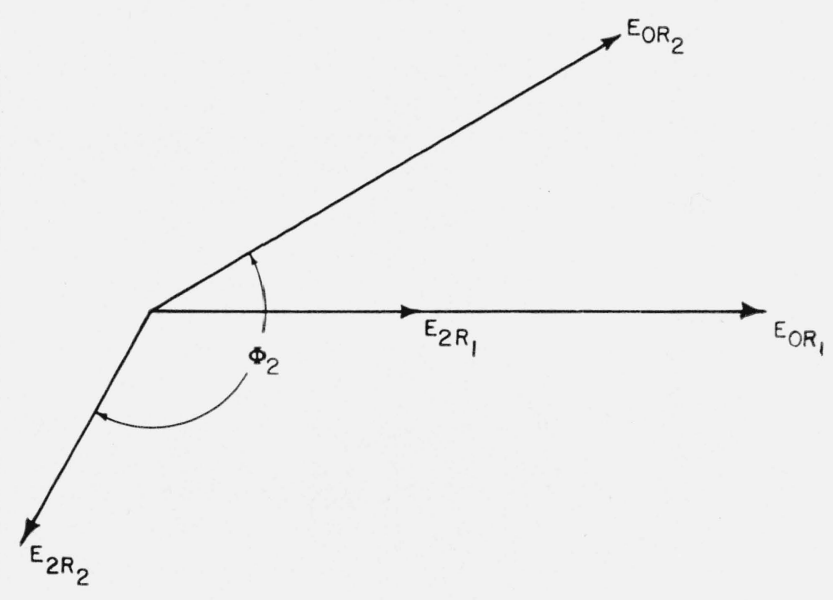

$$
\begin{aligned}
& E_{O R_{1}}=\text { VOLTAGE AT } R_{1} \text { DUE TO TRANSMISSION FROM TO } \\
& E_{O R_{2}}=\text { VOLTAGE AT } R_{2} \text { DUE TO TRANSMISSION FROM TO } \\
& E_{2 R_{1}}=\text { VOLTAGE AT } R_{1} \text { DUE TO TRANSMISSION FROM } T_{2} \\
& E_{2 R_{2}}=\text { VOLTAGE AT } R_{2} \text { DUE TO TRANSMISSION FROM } T_{2}
\end{aligned}
$$

FIGURE 3. Vector relationship of voltages at receiving points $R_{1}$ and $R_{2}$ with transmissions from $T_{0}$ and $T_{2}$. 
frequency of $T_{0}$ lower than the frequency of $T_{2}, \Phi_{2}$ is the angle by which the heterodyne-frequency signal at $R_{1}$ leads the heterodyne-frequency signal at $R_{2}$. The change in heterodyne-frequency phase noted between figures 2 and 3 is

$$
2 \Phi=\Phi_{1}-\Phi_{2}+2 \pi M
$$

where $M$ is an integer.

The above considerations apply whether the transmitting frequency of $T_{0}$ is higher or lower than the transmitting frequencies of $T_{1}$ and $T_{2}$.

The phase change given by eq (2) is equal to the change in phase between the radio-frequency signals at $R_{1}$ and $R_{2}$ when $T_{1}$ is moved halfway around the system to the position occupied by $T_{2}$; this is seen to be true from the following considerations. If $T_{1}$ is moved over a path such that at all times it is at a fixed distance from $R_{1}$, then all vectors shown in figures 2 and 3 will remain fixed except $E_{1 R_{2}}$ (which advances and finally becomes colinear with $E_{2 R_{2}}$ in fig. 3), and the angle swept out by $E_{2 R_{2}}$ is equal to the radio-frequency phase change in the signal from $T_{1}$ (at $R_{2}$ ) as the transmitter moves halfway around the system; this angle is identical to the angle $2 \Phi$. The ambiguity of the value of $\Phi$ must, of course, be resolved by adding the correct number of whole wavelength changes in phase $(M)$, obtained when $T_{1}$ is moved halfway around the system. It should be noted that the above considerations involve only relative phase and change in relative phase. It should also be noted that the phases of the transmissions from $T_{0}$ to $R_{1}$ and $R_{2}$ do not affect the value of $\Phi$, provided that these factors remain constant during the time required to measure $\Phi_{1}$ and $\Phi_{2}$.

The complete system used to make the phasevelocity measurements is shown in block form in figure 4. As in figure $1, R_{1}$ and $R_{2}$ are the two receiving points (antennas) between which the radiowave phase velocity was measured; the transmission from radio transmitter $T_{0}$ combines with the signal from $T_{1}$ (or $T_{2}$ ) to produce heterodyne-frequency signals at $R_{1}$ and $R_{2}$. Radio transmitters $T_{1}$ and $T_{2}$ were located on the extensions of the straight line through $R_{1}$ and $R_{2}$ and provided signals on which

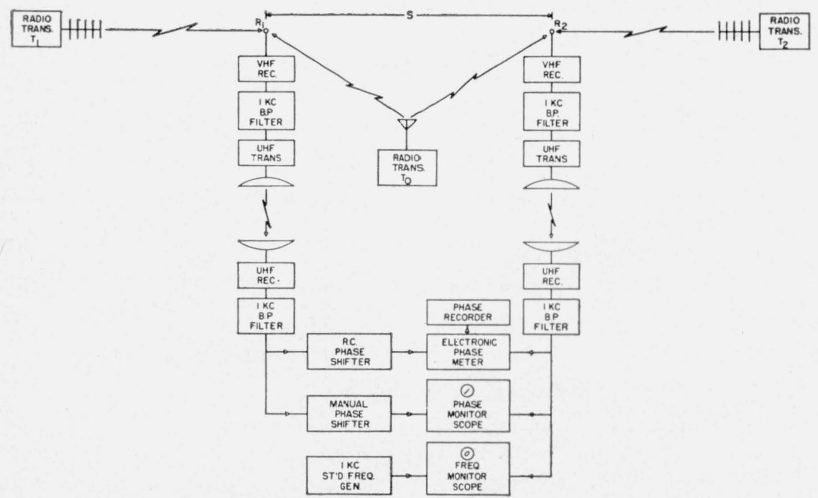

Figure 4. Block diagram of phase-velocity measuring system. the phase-velocity measurements were made. Two types of receiving antennas were used: (1) vertically polarized, unbalanced quarter-wave antennas with base at ground level, and (2) balanced horizontally polarized, half-wave antennas approximately $\lambda / 4$ above the ground.

The following procedure was used when making a phase-velocity measurement: Radio transmitters $T_{0}$ and $T_{1}$ were turned on, and the frequency of $T_{0}$ was adjusted to $172.801 \mathrm{Mc}$. The frequency of $T_{1}$ was then adjusted to $172.800 \mathrm{Mc}$ in terms of the 1-kc heterodyne-frequency signals appearing in the outputs of the radio receivers at $R_{1}$ and $R_{2}$. These 1-kc heterodyne-frequency signals were transmitted via the two UHF radio links to the frequency-monitoring scope and the phase-measuring system. The value of $\Phi_{1}$ (eq 2) was then obtained from the dial of the "manual phase shifter", with this instrument adjusted to give a closed pattern on the "phase monitor oscilloscope." Radio transmitter $T_{1}$ was then turned off and the above procedure was repeated, using $T_{2}$ as the signal source, to give a value for $\Phi_{2}$ in terms of a new setting of the dial on the manual phase shifter (and a closed pattern on the phase monitor scope). From the above values of $\Phi_{1}$ and $\Phi_{2}$ and eq (2), a value for $\Phi$ was obtained, which in turn was used in eq (1) to yield a value for the radio-wave phase velocity between $R_{1}$ and $R_{2}$ for a frequency of $172.800 \mathrm{Mc}$.

Figure 4 shows two (parallel) sets of instruments for measuring relative phases and change in phase. The manual phase-shifter-phase-monitor oscilloscope arrangement was used to obtain accurate, routine measurements of $\Phi_{1}$ and $\Phi_{2}$; the RC (resistancecapacitance) phase-shifter-phase-meter assembly was used to obtain a recording of the total change in phase when radio transmitter $T_{1}$ was moved over a path halfway around the system. This total change in phase was used to resolve the ambiguity in the value of $\Phi$ obtained from eq (2).

Figure 5 is a block diagram of the frequencymonitoring system used to adjust and monitor both the frequency of $T_{0}$ and the 1-kc heterodyne-signal frequency used in making phase measurements of $\Phi_{1}$ and $\Phi_{2}$.

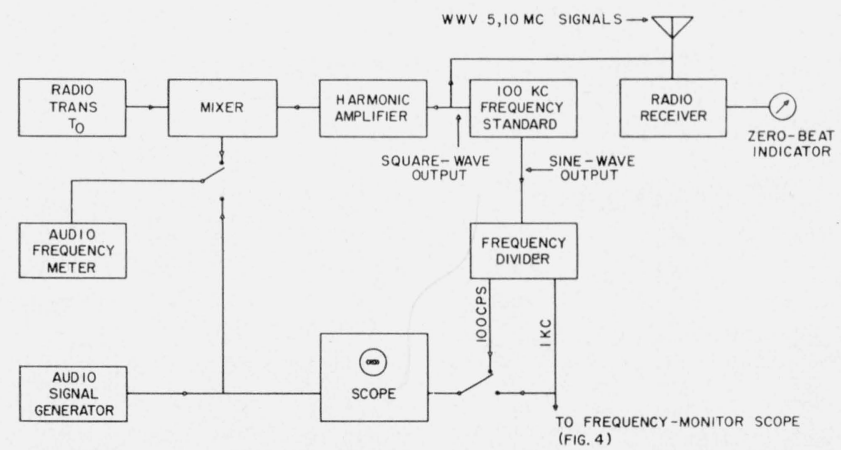

Figure 5. Block diagram of frequency-monitoring system. 
The frequency standard used in this system was a 100-kc crystal oscillator. The frequency of the oscillator was periodically checked and adjusted to \pm 1 part in $10^{7}$ by comparing either its fiftieth or its one-hundredth harmonic with the 5 - or $10-\mathrm{Mc}$ WWV signal, respectively, by means of a radio receiver. Allowing for the ionospheric doppler effect, it is estimated that the frequency of the WWV signal as received was accurate to 1 part in $10^{7}$. The frequency of radio transmitter $T_{0}$ was adjusted to be within 1 part in $10^{7}$ of the $100-k e$ frequency standard by mixing the output of the $T_{0}$ oscillator $(7.2000417 \mathrm{Mc})$ with the seventy-second harmonic of the $100-\mathrm{kc}$ frequency standard to give a mixer output of $41.7 \mathrm{cps}$. The accuracy of the frequency meter was checked to within $0.5 \mathrm{cps}$ against the 100 -cps output from the frequency divider, which in turn was controlled by the 100-kc output from the frequency standard.

As a precautionary measure, the audiosignal generator was used to check the frequency-divider output in order to make sure that the frequencydivider ratios were exactly 100 to 1 and 1,000 to 1 .

\section{Consideration of Factors Governing Accuracy}

The over-all accuracy of the phase-velocity measurements depends upon the accuracy with which the factors in eq (1) can be determined.

The frequency, $f$, was adjusted in terms of station WWV frequency to within 1 part in $10^{7}$. Allowing for frequency drift in the 100-kc (local oscillator) frequency standard and also for drift of $T_{0}, T_{1}$, $T_{2}$ during the short time (approximately $2 \mathrm{~min}$.) required to make a phase-velocity measurement, it is estimated that the accuracy of the frequency term in eq (1) was 5 parts in $10^{7}$, or better.

The distance, $S$, between the receiving points $\left(R_{1}\right.$ and $R_{2}$ ) was measured by means of three standard invar 50-m tapes. These tapes were standardized at the National Bureau of Standards, and the actual survey and calculation of this distance was carried out by using the U. S. Coast and Geodetic survey techniques described in "Manual of Geodetic Triangulation," special publication 247. The standard deviation of the measurements of distance $S$ was 2 parts in $10^{6}$. The calculated straight-line distance between points $R_{1}$ and $R_{2}$ differs from the greatcircle distance over the surface of the earth by less than 1 part in $10^{8}$, a negligible amount when $S$ equals $1,500 \mathrm{~m}$.

The factors involved in the measurement of the phase change $\Phi$ are numerous and are listed as follows:

(a) The actual paths traversed by the radio waves at the surface of the earth are curved because of the variation of the index of refraction of the air with altitude [20]. Normal atmospheric conditions are such that the radius of curvature of the radiowave paths is greater than the radius of the earth, and if we pessimistically estimate that the radius of curvature of the radio rays is equal to one-fifth of the earth's radius, we find that the calculated error in $\Phi$, for a path length of $1,500 \mathrm{~m}$, is of the order of 1 part in $10^{7}$ and, therefore, can be ignored.

(b) Spurious signals from $T_{1}$ (and $T_{2}$ ) to receiving: points $R_{1}$ and $R_{2}$ can alter the value of $\Phi$ and can cause errors in the measurement of the phase velocity. These spurious signals usually are due to multipath reflections from nearby objects, such as power lines, large metallic objects, mountains, etc. For the conditions under which the phase-velocity measurements listed in this paper were made (using 5-element Yagi transmitting antennas at $T_{1}$ and $T_{2}$ ), it was determined experimentally that this multipath effect on $\Phi$ was approximately 1 electrical degree, which in turn corresponds to an error in phasevelocity measurement of 1.7 parts in $10^{6}$, for a distance of $1,500 \mathrm{~m}$ between $R_{1}$ and $R_{2}$. The test for multipath phase error consisted of moving each of the radio transmitters $T_{1}$ and $T_{2}$ along the extensions of the receiving-point line; an oscillating variation of the phase difference between the signals at $R_{1}$ and $R_{2}$ indicates the presence of and the amount of multipath phase error.

Tests showed negligible multipath phase errors due to the presence of the trucks that housed the equipment and the metal enclosures that housed the radio receivers, but there was definite evidence that sufficient radiation was reflected from nearby mountains ( 5 to 20 miles distant) to cause the multipath phase error of 1 degree noted above. This phase error was increased to approximately 8 degrees when omnidirectional antennas were used to transmit from $T_{1}$ and $T_{2}$.

(c) The true value of $\Phi$ is the maximum value obtained by moving a radio transmitter from a position on one extension of the line through the receiving points, halfway around the system to the other extension of the receiving-point line. The start and stop points of the path of the moving transmitter on the extensions of the receiving-point line correspond to the fixed positions of radio transmitters $T_{1}$ and $T_{2}$, respectively. It was found experimentally that the positions of $T_{1}$ and $T_{2}$, which gave a maximum value for $\Phi$, were on the optical line through receiving points $R_{1}$ and $R_{2}$. The positioning of $T_{1}$ and $T_{2}$ was sufficiently accurate to insure that the error in the measurement of $\Phi$ was less than 2.5 parts in $10^{7}$. It should be noted that an error in the positioning of $T_{1}$ or $T_{2}$ has the effect of giving a measured value of $\Phi$ that is always smaller than its true value.

(d) The phase velocity of a radio wave varies considerably in the "near-region" $[10,11,12,13,21]$ of the transmitting antenna. Tests were made to determine the limits of the near-region, and the results indicated that the phase velocity approached a constant value, within 5 parts in $10^{7}$, at a distance of 500 wavelengths or more from the transmitting antenna. Phase-velocity measurements considered in this work were made at a distance of 500 wavelengths, or more, from the transmitting antenna, and hence are sufficiently free of near-region effects.

(e) One source of error in the measurement of $\Phi$ was found to be due to spurious pickup by the cables 
connected to the receiving antennas at $R_{1}$ and $R_{2}$. Unfortunately, the existence of this condition was not definitely established until the equipment had been moved from the special field site at which the phase-velocity measurements were carried out. This error was found to vary considerably, depending upon the arrangement of the receiving-antenna cables, and it was not possible to duplicate exactly the original conditions of the phase-velocity measurements; a pessimistic estimate of this error is 5 parts in $10^{6}$. This cable-pickup error applies only to the unbalanced quarter-wave receiving antennas and not to the balanced half-wave antennas.

(f) Tests made on the two VHF radio receivers (connected to receiving points $R_{1}$ and $R_{2}$ ) showed that the relative phase of the heterodyne-frequency output was dependent upon the signal level of the radio-frequency input to the receivers and also upon the equivalent percentage modulation of the input signal; hence a phase error was introduced by the radio receivers when transmissions were switched from $T_{1}$ to $T_{2}$ because of the resultant change in signal levels at $R_{1}$ and $R_{2}$. Corrections were made for the radio-receiver phase errors in the calculated values of the free-space phase velocities listed in this report. The estimated error in the phase-velocity measurements due to the phase characteristic of the VHF radio receivers was 1 part in $10^{6}$, after proper corrections had been made for these receiver phase characteristics.

(g) A series of comprehensive tests on the system indicated that there was no measurable error due to any form of cross-modulation between any sections of the system. Furthermore, the phase stability and the relative-phase accuracy of the system were found to be sufficiently good to insure a phase-change measurement of $\Phi$, which was accurate to within 1 electrical degree. This accuracy in the measured value for $\Phi$ corresponds to a phase-velocity measurement accuracy of 1.7 parts in $10^{6}$, for a receiver-point spacing $\left(R_{1}\right.$ to $\left.R_{2}\right)$ of $1,500 \mathrm{~m}$.

(h) The effect of the diameter and the length of the receiving antennas on the value of $\Phi$ was determined experimentally. The diameters of the receiving antennas were varied from 0.010 to 0.25 in. and the lengths were varied from $\lambda / 20$ to $\lambda / 4$. The results indicated no measurable effect on the value of $\Phi$ due to these variations.

As the velocity of propagation of radio waves through the air depends upon the refractive index of the air, it is necessary to measure the atmospheric pressure, temperature, and vapor pressure in order to obtain a calculated value for the index of refraction of the air. It should be noted that the velocity measurements were made by using a monochromatic source, and hence the wave index of refraction applies in this case.

The estimated accuracies of measurement of air pressure, temperature, and relative humidity are: pressure, 1 millibar; temperature, $1^{\circ} \mathrm{C}$; relative humidity, 3 percent. Using the relationship [14],

$$
(n-1) 10^{6}=N=\left\{\frac{77.6}{T}\left(p+4810 \frac{e}{T}\right\},\right.
$$

where

$n=$ index of refraction of air,

$p=$ total atmospheric pressure, in millibars,

$e=$ partial pressure of water vapor in air, in millibors,

$T=$ absolute temperature, $\operatorname{deg} \mathrm{K}={ }^{\circ} \mathrm{C}+273^{\circ}$.

The estimated accuracy of the calculated value for the index of refraction of the air is 4 parts in $10^{6}$.

The atmospheric pressure, temperature, and relative-humidity measurements were made in the vicinity of the radio-wave path between receiving points $R_{1}$ and $R_{2}$, at a distance of $1 \mathrm{~m}$ above the ground; hence these measurements represent a localized check and not an average or integrated value of the air constants along the actual path of the radio waves between $R_{1}$ and $R_{2}$.

It is of interest to note at this point that at times when the wind was extremely gusty (and crosswise of the path from $R_{1}$ to $R_{2}$ ) the measured value of $\Phi$ quite often fluctuated suddenly in synchronism with the gusts of wind. The maximum fluctuations in $\Phi$ corresponded to an apparent change in the index of refraction of air of approximately 10 parts in $10^{6}$.

Table 1 is a summary of the various factors that influenced the accuracy of the phase-velocity measurements, together with the estimated limits of errors of measurement in these factors. Two types of errors are listed in this table: one type is a fixed (or systematic) error, and the other type of error is random and varies in amount from one measurement of phase velocity to another.

TABLE 1. Factors which influenced accuracy of phase-velocity measurements

\begin{tabular}{|c|c|}
\hline Factor & $\begin{array}{l}\text { Estimated limit to resulting } \\
\text { error of measurement }\end{array}$ \\
\hline $\begin{array}{l}\text { Measurement of the radiofrequency, } f \\
\text { Surveyed distance, } S \\
\text { Curvature of radio beam } \\
\text { Multipath effect } \\
\text { Positions of } T_{1} \text { and } T_{2} \\
\text { Receiving-antenna cable-pickup error } \\
\text { Phase characteristics of VHF radio receivers. } \\
\text { Phase-measuring system } \\
\text { Measurement of the refractive index of air }\end{array}$ & $\begin{array}{l}\text { a } 0.5 \times 10^{-6} \\
2 \\
0.01 \\
\text { a } 1.7 \\
0.25 \\
\text { a } 5 \\
\text { a } 1 \\
\text { a } 1.7 \\
\text { a } 4.0\end{array}$ \\
\hline $\begin{array}{l}\text { Total estimated maximum systematic } \\
\text { (bias) error }\end{array}$ & $2.25 \times 10^{-6}=0.7 \mathrm{~km} / \mathrm{sec}$ \\
\hline
\end{tabular}

a These errors are likely to vary from one set of phase-velocity measurements to another, and therefore, are components of the over-all random error.

\section{Experimental Results}

Three sites were used to carry out the phasevelocity measurements. The first site was at the obsolete Blue Ridge Airport near Willard, Va., and was used to make preliminary tests on the system for sources of systematic errors, reliability of operation, and phase stability of the equipment. The equipment was set up in the center of a level area clear of objects in all directions to a distance of at least $250 \mathrm{~m}$. The distance between the receiving points $R_{1}$ and $R_{2}$ was $200 \mathrm{~m}$. Tests at this site indicated the possibility of large phase errors due to reflections from nearby objects, such as power lines, metal buildings, woods, etc. [15]. For some positions of the radio transmitters 
$T_{1}$ and $T_{2}$, along the extensions of the receiving-point line, the phase error in the measured value for $\Phi$ was found to be as much as 50 electrical degrees; this error in phase measurement corresponded to an error in the measurement of the radio-wave phase velocity of 1 part in 16,000 .

The second site used to make phase-velocity measurements was a dry lake bed 8 miles south of Willcox, Ariz., at an altitude of $4,100 \mathrm{ft}$ above sea level. The system was set up on the south end of the lake bed, approximately 4 miles east of Cochise, Ariz., in an area where the ground was level to within \pm 2 in. and was completely devoid of vegetation. The minimum distance to nearby reflexing objects (excluding trucks) was at least 4 miles. Line of sight conditions existed between the receiving and the transmitting antennas. The geometry of the system was as shown in figure 1 , with the receiving-point line extending north and south. The distance $S$ was varied, depending upon the type of test being made; for the reported phase-velocity measurements, two values of $S$ were used: 850.0013 and $1500.0018 \mathrm{~m}$. The distances from $T_{0}$ to $R_{1}$ and $T_{0}$ to $R_{2}$ (see fig. 4 ) were each approximately $1,400 \mathrm{~m}$, and $T_{0}$ was located on the west side of the receiving-point line. The distances from $T_{1}$ to $R_{1}$ and from $T_{2}$ to $R_{2}$ were varied during the tests but for all precise measurements of the phase increment $\Phi$ these distances were greater than 500 wavelengths; that is, greater than $850 \mathrm{~m}$.

After a series of preliminary tests on the system, a series of phase-velocity measurements were made at this second site over a period of 3 weeks during the months of April and May 1953. The phase-velocity measurements were supplemented by recorded values of the atmospheric temperature, pressure, and relative humidity. The radio-frequency signal levels at $R_{1}$ and $R_{2}$ were also noted and recorded in terms of the VHF radio-receiver first-limiter grid current. The results of these tests are shown in table 2 . The value for $\Phi$ (as measured) was obtained from eq (2). The whole-number wavelengths between $R_{1}$ and $R_{2}$ were measured by recording the total change in phase differential as radio transmitter $T_{1}$ was moved halfway around the system.
For a receiving-point spacing $(S)$ of $1500.0018 \mathrm{~m}$, the whole-number wavelength distance was 864 wavelengths, and for $S=850.0013 \mathrm{~m}$, the wholenumber wavelength distance was 490 wavelengths; corresponding values for $M$ (eq 2) were 1,729 wavelengths and 980 wavelengths, respectively.

From the above considerations the free-space phase velocity in kilometers per second, as calculated from eq (1) (with $\Phi$ in degrees), is

$$
\begin{aligned}
V & =\frac{360 \times 172.8 \times 10^{6} \times 1500.0018 \times n}{10^{3} \times \Phi} \\
& =\frac{93,312,114 \times 10^{3} \times n}{\Phi}
\end{aligned}
$$

for $S=1500.0018 \mathrm{~m}$ and,

$$
\begin{aligned}
V & =\frac{360 \times 172.8 \times 10^{6} \times 850.0013 \times n}{10^{3} \times \Phi} \\
& =\frac{52,876,881 \times 10^{3} \times n}{\Phi}
\end{aligned}
$$

for $S=850.0013 \mathrm{~m}$.

The data in table 2 were obtained with the distance from $T_{1}$ to $R_{1}$ (and $T_{2}$ to $R_{2}$ ) equal to $1,000 \mathrm{~m}$ and with the transmitter antennas $3 \mathrm{~m}$ above ground level. The receiving antennas $\left(R_{1}\right.$ and $\left.R_{2}\right)$ were only $0.2 \mathrm{~m}$ above ground, and as the received signals were the resultants of the three modes of transmission, the direct, ground-reflected, and surface waves [16], it was necessary to apply a correction to the measured phase velocity. This calculated correction was found to be $-0.6 \mathrm{~km} / \mathrm{sec}$.

During July, August, and September 1953 the equipment was set up at the third test site, at Sterling, Va., and a comprehensive set of system tests were made. These tests showed that cross-modulation phase errors in the system were less than a measurable value, that is, less than 0.1 electrical degree. These tests also indicated that there was a

\begin{tabular}{|c|c|c|c|c|c|c|}
\hline 1953 & $\begin{array}{l}\text { Number of } \\
\text { measurements }\end{array}$ & $\begin{array}{l}\text { Distance between } \\
\text { receiving points } \\
R_{1} \text { and } R_{2}\end{array}$ & Polarization & $\begin{array}{c}\text { Daily average } \\
\text { value of } N \\
N=(n-1) 10^{6}\end{array}$ & $\begin{array}{l}\text { Range of calculated values } \\
\text { of free-space phase ve- } \\
\text { locity of radiowaves }\end{array}$ & $\begin{array}{l}\text { Daily average val- } \\
\text { ue of free-space } \\
\text { phase velocity of } \\
\text { radiowaves }\end{array}$ \\
\hline $\begin{array}{r}\text { Apr. } 27 \\
28 \\
29 \\
30\end{array}$ & $\begin{array}{r}3 \\
1 \\
25 \\
3\end{array}$ & $\begin{array}{c}m \\
1500.0018 \\
1500.0018 \\
1500.0018 \\
1500.0018\end{array}$ & $\begin{array}{l}\text { Vertical _....... } \\
\text { do do }\end{array}$ & $\begin{array}{l}243.4 \\
271.2 \\
248.3 \\
252.3\end{array}$ & $\begin{array}{l}\mathrm{km} / \mathrm{sec} \\
299791.5 \text { to } 299791.8 \\
299791.4 \text { to } 299791.4 \\
299792.2 \text { to } 299797.5 \\
299792.3 \text { to } 299797.7\end{array}$ & $\begin{array}{l}\mathrm{km} / \mathrm{sec} \\
299791.7 \\
299791.4 \\
299794.0 \\
299795.5\end{array}$ \\
\hline 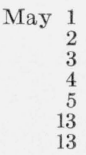 & $\begin{array}{r}11 \\
7 \\
8 \\
39 \\
4 \\
4 \\
5\end{array}$ & $\begin{array}{r}1500.0018 \\
1500.0018 \\
1500.0018 \\
1500.0018 \\
850.0013 \\
850.0013 \\
1500.0018\end{array}$ & 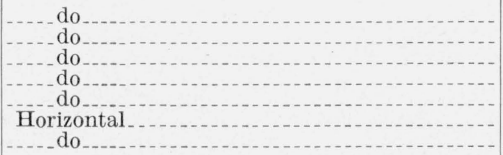 & $\begin{array}{l}257.6 \\
243.0 \\
247.5 \\
257.1 \\
251.6 \\
245.3\end{array}$ & $\begin{array}{l}299789.3 \text { to } 299800.0 \\
299797.1 \text { to } 299801.0 \\
299799.9 \text { to } 299802.0 \\
299798.6 \text { to } 299800.1 \\
299792.8 \text { to } 299794.5 \\
299789.4 \text { to } 299796.3\end{array}$ & $\begin{array}{l}299794.9 \\
299800.0 \\
299801.1 \\
299799.4 \\
299793.8 \\
299794.8\end{array}$ \\
\hline
\end{tabular}
phase error due to spurious pickup of the receivingantenna cables when using an unbalanced quarter-

TABLE 2. Summary of results of radio-wave phase-velocity measurements

Weighted mean value (see text) of free-space phase velocity, based on 110 measurements, $299795.7 \mathrm{k} \cdot \mathrm{n} / \mathrm{sec}$.

Geometrical correction (transmitting antenna $3 \mathrm{~m}$ high, receiving antenna $0.2 \mathrm{~m}$ high), plus multimode transmission correction, $-0.6 \mathrm{~km} / \mathrm{sec}$.

Resultant mean value of free-space phase veloeity of radiowaves, $299795.1 \mathrm{~km} / \mathrm{sec}$. 
wave vertical antenna and negligible phase error for a balanced half-wave horizontal antenna. This receiving-antenna cable pickup error was estimated to be 5 parts in $10^{6}$ for the phase-velocity measurements made at the Willcox, Ariz. site and is listed in table 1.

Further tests at the Sterling site disclosed that the relative $\mathrm{p}$ hase of the VHF radio-receivers $\left(R_{1}\right.$ and $\left.R_{2}\right)$ heterodyn e-frequency output varied with the radiofrequency signal-level input to the receivers. A set of phase-correction curves were drawn, based on the results of these tests, and proper phase corrections were made for these phase errors in the radio receivers. These corrections were based on the known. (and recorded) radio-frequency signal-input levels and the equivalent amplitude modulation.

\section{Discussion}

The phase velocity of propagation of radio waves in free space, as determined experimentally in the work covered by this report, is $299795.1 \pm 3.1 \mathrm{~km} / \mathrm{sec}$. This is a weighted average, or mean value, based on 110 independent measurements made during 10 days and is calculated by weighting each of the 10 daily means equally. However, this weighted mean for the phase-velocity measurement is subject to two types of errors. One type is a systematic error (or bias), which appears in approximately the same amount in every measurement and reflects the inherent limitations of the measuring system to measure the true value of the phase velocity of radio waves. The other type of error is random, and appears in different amounts randomly in each measurement of the phase velocity.

Assigning equal weights to each daily mean i justified on the following considerations. In terms of the random variations, the data indicate that measurements taken within a day tend to show better agreement than measurements taken on different days. Thus these measurements contain two sources of variability [17]. One source, called the "within days variation" or the "internal precision", reflects the degree of agreement between repeated measurements made on the same day. The other source of variability, termed the "between days variation" or the "external precision", reflects how well measurements made on different days agree with each other. The internal and external variability can be expressed quantitatively by $\sigma_{1}$ and $\sigma_{2}$, respectively. Both of these quantities are inversely proportional to their associated precisions and are defined as follows: If an infinite number of measurements were made on one day, then the standard deviation $\left(\sigma_{1}\right)$ of the measurements referred to the daily average will reflect how well these measurements agree with each other. Now, if this process is continued for an infinite number of days, the standard deviation $\left(\sigma_{2}\right)$ of the daily averages referred to the grand average will reflect how well measurements made on different days agree with each other. However, as only a finite amount of data is available, it is necessary to estimate the quantities $\sigma_{1}$ and $\sigma_{2}$. Table 3 shows the numerical computations for estimating $\sigma_{1}$ and $\sigma_{2}[18]$.
The standard deviation for a daily average based on $n$ measurements is given by $\sqrt{\left(\sigma_{1}^{2} / n\right)+\sigma_{2}^{2}}$. For proper weighting, each daily average should be weighted in proportion to $1 /\left\{\left(\sigma_{1}^{2} / n\right)+\sigma_{2}^{2}\right\}$. However, if $\sigma_{2}^{2}$ is large compared to $\sigma_{1}^{2} / n$, then the daily averages can be weighted equally to give a grand mean that will not differ appreciably from the mean that would be obtained by (exact) proper weighting.

Table 1 lists the possible sources of errors, with an estimated limiting value for the effect of each source on the reported figure for the phase velocity of radio waves. From table 1 the total estimated systematic error is 2.25 parts in $10^{6}= \pm 0.7 \mathrm{~km} / \mathrm{sec}$. This (systematic) error can be either positive or negative, and unless there is good evidence of its polarity, the safe procedure is to assume that it introduces an error spread equal to twice its above value, centered about the mean value.

TABLE 3. Analysis of variance

\begin{tabular}{|c|c|c|c|c|}
\hline Source & $\begin{array}{c}\text { Degrees } \\
\text { of freedom }\end{array}$ & $\begin{array}{l}\text { Sums of } \\
\text { squares of } \\
\text { deviations }\end{array}$ & $\begin{array}{c}\text { Mean. } \\
\text { square } \\
\text { deviation }\end{array}$ & $\begin{array}{c}\text { Expected } \\
\text { value [19] } \\
\text { of mean } \\
\text { square }\end{array}$ \\
\hline $\begin{array}{l}\text { Between days.......... } \\
\text { Within days.......... }\end{array}$ & $\begin{array}{c}9 \\
100\end{array}$ & $\begin{array}{l}927.41 \\
318.37\end{array}$ & $\begin{array}{r}103.0456 \\
3.1837\end{array}$ & $\begin{array}{c}\sigma_{1}^{2}+9.701 \sigma_{2}^{2} \\
\sigma_{1}^{2}\end{array}$ \\
\hline \multicolumn{5}{|c|}{ Estimated value of $\sigma_{2}^{2}=\frac{103.0456-3.1837}{9.701}=10.29$} \\
\hline
\end{tabular}

From table 2 the standard deviation of the weighted mean (of the 110 measurements) is $1.05 \mathrm{~km} / \mathrm{sec}$, which is a measure of the random error or of the precision of the weighted mean, calculated from the relationship.

$$
\text { Std. dev. }=\frac{1}{m} \sqrt{\sigma_{1}^{2}\left(\frac{1}{n_{1}}+\frac{1}{n_{2}}+\ldots+\frac{1}{n_{m}}\right)+m \sigma_{2}^{2}}
$$

where $m$ is the number of days; $n_{1}, n_{2}$, etc. are the number of measurements taken on the respective days; $\sigma_{1}$ is the standard deviation for any one measurement - calculated by referring each measurement to its own daily average; and $\sigma_{2}$ is the standard deviation of a daily average referred to the mean of all the daily averages.

A 95-percent confidence interval for the mean of an infinite family of such determinations is 299795.1 $\pm 2.4 \mathrm{~km} / \mathrm{sec}$; that is, if the same experiment were repeated 100 times and the resulting means and associated confidence intervals calculated, then, on the average, 95 of these intervals will cover the "true value," where the true value is the average value obtained from an infinite number of measurements.

Hence to find a conservative estimate of the accuracy for the above measurements of the free-space phase velocity of radio waves, the maximum estimated systematic error of $0.7 \mathrm{~km} / \mathrm{sec}$ has been added to one-half the length of the confidence interval of $\pm 2.4 \mathrm{~km} / \mathrm{sec}$ to give the limits of accuracy as \pm 3.1 $\mathrm{km} / \mathrm{sec}$, which applies to the above-reported mean 
value of the measurement of the free-space phase velocity of radio waves.

It should be noted that a 50-percent confidence interval for the mean value of the measurements would be $299795.1 \pm 0.7 \mathrm{~km} / \mathrm{sec}$, and a corresponding estimate of the accuracy for the above measurement of the free-space phase velocity of radio waves would be $299795.1 \pm 1.4 \mathrm{~km} / \mathrm{sec}$.

\section{Conclusions}

From the results of the measurements made in this work, shown in table 2 , and from the estimated value for the total maximum systematic error, shown in table 1, it is concluded that the free-space phase velocity of VHF radio waves is $299795.1 \pm 3.1 \mathrm{~km} /$ sec.

A study of the factors in table 1 indicates that the over-all accuracy of the measurement of the freespace phase velocity could be improved by equipment modifications and by improved techniques; the accuracy of this phase-velocity measurement seems to be limited by the accuracy with which the "true" (or "effective") value of the refractive index of air can be measured over the path traversed by the radio waves.

Table 4 lists the values obtained for the velocity of propagation of electromagnetic waves by various workers during the past half century.

TABie 4. Some published values of the velocity of electromagnetic waves

\begin{tabular}{|c|c|c|c|}
\hline Date & Observer & $\begin{array}{l}\text { Velocity, } \mathrm{km} / \mathrm{sec} \text {, } \\
\text { in free space }\end{array}$ & Method \\
\hline 1906 a & Rosa and Dorsey [2] ... & $299781 \pm 30$ & $\begin{array}{l}\text { Ratio of esu to } \\
\text { emu. }\end{array}$ \\
\hline 1926 & Michelson [7] & $299796 \pm 4$ & Rotating mirror. \\
\hline 1935 & $\begin{array}{l}\text { Michelson, Pease, and } \\
\text { Pearson [1]. }\end{array}$ & $299774 \pm 11$ & $\begin{array}{l}\text { Rotating mirror } \\
\text { in vacuum. }\end{array}$ \\
\hline 1941 & Anderson $[3]$ & $299776 \pm 14$ & $\begin{array}{l}\text { Modulated light } \\
\text { beam. }\end{array}$ \\
\hline 1949 & Aslakson $[22]$ & $299792.4 \pm 2.4$ & Shoran (radar). \\
\hline 1950 & Essen $[6]$ & $299792.5 \pm 3$ & Resonant cavity. \\
\hline 1950 & Bol $[5]$ & $299789.3 \pm 0.4$ & Do. \\
\hline 1951 & Bergstrand [23]. & $299793.1 \pm .2$ & $\begin{array}{l}\text { Modulated light } \\
\text { beam }\end{array}$ \\
\hline 1951 & Aslakson $[24]$ & 299794. $2 \pm 1.9$ & Shoran (radar). \\
\hline 1952 & Froome [9] & $299792.6 \pm 0.7$ & $\begin{array}{l}\text { Microwave radio } \\
\text { interferometer. }\end{array}$ \\
\hline
\end{tabular}

a In an unpublished NBS memorandum from F. B. Silsbee to I. C. Gardner (April 22, 1954) Dr. Silsbee shows that if corrections are based on recently measured effects of humidity on the index of refraction for air, and if the 1948 value for the adopted International ohm is used, then the Rosa and Dorsey value becomes $V=299800 \pm 31 \mathrm{~km} / \mathrm{sec}$.

The measured value of the free-space phase velocity of radio waves obtained in this work checks the results obtained by reasonant-cavity methods $[5,6]$ and by SHF interferometer methods [9] but does not check very well with some of the work done on the measurement of the velocity of light $[1,3,8]$.

The author expresses his appreciation to the following members of the National Bureau of Standards who have assisted in carrying out this work: John C. Onda, Louis R. Russell, A. C. Tavenner, William O. Hutchison, N. Rahal, and J. Donhaiser. We are also grateful to Myron H. Allen of Safford, Ariz., who contributed a good deal of time and effort in locating a site suitable for the tests. H. W. Hemple, A. J. Hoskinson, and other members of the U. S. Coast and Geodetic Survey, Washington, D. C. have been extremely cooperative in giving advice and lending equipment for use on this project. W. J. Youden and Marvin Zelen of the Statistical Engineering Laboratory, National Bureau of Standards, deserve credit for guidance of the statistical analysis of the results of this work.

\section{References}

[1] A. A. Michelson, F. G. Pease, and F. Pearson, Velocity of light in a partial vacuum, Astrpohys. J. 82, 26 (1935).

[2] E. B. Rosa and N. E. Dorsey, Bul. BS 3, 433 (1907) S65

[3] W. C. Anderson, Final measurements of the velocity of light, J. Opt. Soc. Am. 31, 187 (1941).

[4] R. A. Smith, E. Franklin, and F. B. Whiting, Accurate measurement of the group velocity of radio waves in the atmosphere, using radar techniques, J. Inst. Elec. Engrs. (London) 94, pt. III, 391 (1947).

[5] Kees Bol, A determination of the speed of light by the resonant cavity method, Phys. Rev. 80, 298 (October $15,1950)$

[6] L. Essen, The velocity of propagation of electromagnetic waves derived from the resonant frequencies of a cylindrical cavity resonator, Proc. Roy. Soc. (London) [A] 204, 260 (1950).

[7] N. Ernest Dorsey, The velocity of light, Trans. Am. Phil. Soc. [V] 34, 109 (1944).

[8] D. H. Rank, R. P. Ruth, K. L. Vander Sluis, Precision determination of the velocity of light derived from a band spectrum method, J. Opt. Soc. Am. 42, 693 (1952).

[9] K. D. Froome, Determination of the velocity of short electromagnetic waves by interferometry, Proc. Roy. Soc. (London) [A] 213, 123 (1952).

[10] J. L. Alpert, V. A. Migulin, and P. A. Ryasin, Investigation of the phase structure of the electromagnetic field and the velocity of radio waves, J. Phys. (U. S. S. R.) 4, 13 (1941).

[11] J. L. Alpert and B. Gorozhankin, Experimental investigation of the structure of an electromagnetic field over the inhomogeneous earth's surface, J. Phys. (U.S.S. R.) 9, 115 (1945)

[12] K. A. Norton, A new source of systematic error in radio navigation systems requiring the measurement of the relative phases of the propagated waves, Proc. Inst. Radio Engrs. 35, 284 (March 1947).

[13] A. B. Schneider, Phase variations with range of the ground wave signal from c. w. transmitters in the $70-$ $130 \mathrm{kc} / \mathrm{s}$ band, J. British Inst. Radio Engrs. 12, 181 (March 1952).

[14] Ernest K. Smith and Stanley Weintraub, The constants in the equation for atmospheric refractive index at radio frequencies, Proc. Inst. Radio Engrs. 41, 1035 (August 1953).

[15] R. Bateman, E. F. Florman, and A. Tait, A source of error in radio phase measuring systems, Proc. Inst. Radio Engrs. 38, 612 (June 1950).

[16] K. A. Norton, The calculation of ground-wave field intensity over a finitely conducting spherical earth, Proc. Inst. Radio Engrs. 29, 623 (December 1941).

[17] Raymond T. Virge, The calculation of errors byi the method of least squares, Phys. Rev. 40, 207 (1932).

[18] Anderson and Bancroft, Statistical theory in research, ch. 22 (McGraw-Hill Book Co., Inc., New York, N. Y., 1952).

[19] Statistical Research Group, Columbia Unviersity, Selected techniques of statistical analysis, ch. 8, sec. 5.2 (MeGraw-Hill Book Co., Inc., New York, N. Y., 1947). 
[20] P. A. Sheppard, The structure and refractive index of the lower atmosphere, p. 37 in Meteorological Factors in Radio Wave Propagation, Report of a conference held on April 8, 1946, at the Royal Institution, London, by the Physical Society and the Royal Meteorological Society.

[21] H. H. Skilling, Fundamentals of electric waves, 2d ed., pp. $164-171$ (1948).

[22] Carl I. Aslakson, Can the velocity of radio waves be meas ured by Shoran? Trans. Am. Geo. Union 30, No. 4 (August 1949)

[23] Erik Bergstrand, Arkiv Fysik (Stolkholm) Band 3, No. 26, 479 (1951)

[24] Carl I. Aslakson, New determination of the velocity of radio waves, Trans. Am. Geo. Union 32, 813 (1951).

\section{Appendix -Equipment}

Figure 6 shows the type of quarter-wave vertical antennas used at receiving points $R_{1}$ and $R_{2}$. This assembly was provided with a plumb-bob attachment beneath the antenna base arranged so that the vertical axis of the plumb bob coincided with the vertical axis of the antenna. The lateral position of the antenna was adjusted to bring the point of the plumb bob over the benchmark inscribed on the copper plate on top of the wooden ground stake shown in the figure. The antenna proper was mounted normal to the adjustable portion of the base, which in turn was provided with adjustment leveling screws and a set of right-angle spirit levels.

Tests on the above antenna showed that this antenna could be set up in the field so that the top end of the antenna was within $\pm 0.50 \mathrm{~mm}$ of its true vertical position, and the lateral position of the antenna vertical axis (at the antenna base) could be set to within $\pm 0.20 \mathrm{~mm}$ of the benchmark.

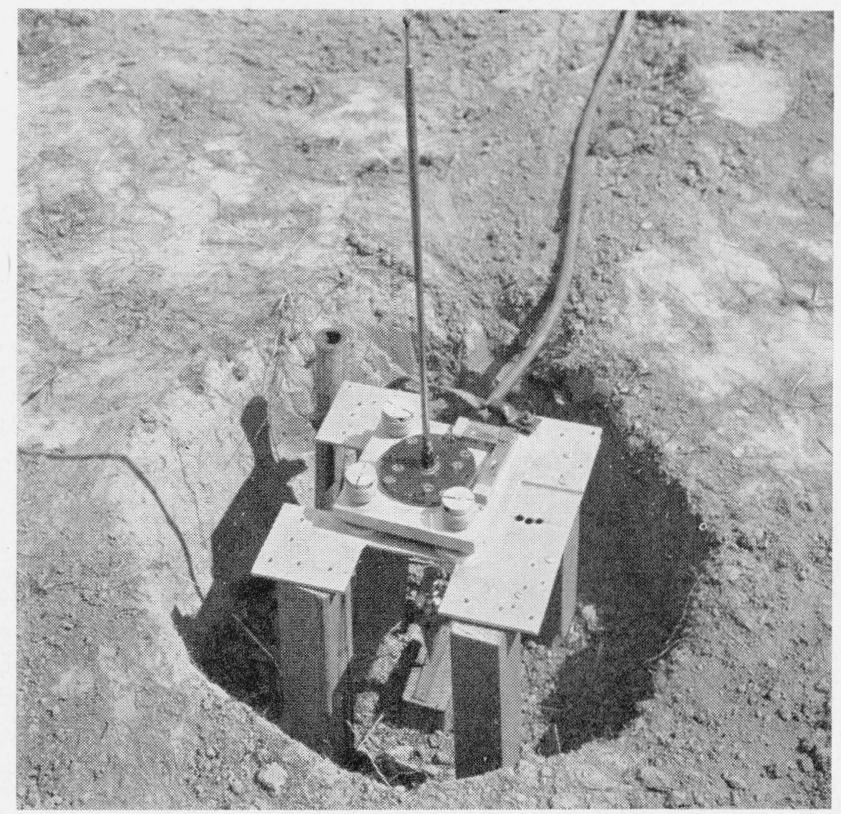

FiguRE 6. Quarter-wave vertical receiving antenna.
Double-shielded 50-ohm cable was used to connect the receiving antenna to the radio receiver. This cable, shown in figure 6 , was $150 \mathrm{ft}$ long and was placed on the ground at right angles to the line through the receiving antennas and led to the radio receiver in the shelter shown in figure 8 .

The horizontal half-wave balanced receiving antenna and balanced-to-unbalanced transformer is shown in figure 7. This antenna was positioned laterally over the benchmarks by means of a plumb bob suspended from the center of the antenna. The horizontal position of the antenna was checked by means of a carpenter's level, and the azimuth of the antenna, relative to the line through the receivingantenna centers, was checked by means of a square. The estimated accuracy of setting of this antenna was $\pm 1.0 \mathrm{~mm}$.

Figure 8 shows one of the two metal enclosures that housed the VHF radio receivers, 1-kc band-pass filters, and the UHF radio transmitters (indicated in fig. 4). This enclosure was also used to house a set of storage cells for battery operation of the equipment. The VHF radio receiver was a commercia] FM type, modified for amplitude-modulation reception and arranged so that the audio output and the first-limiter grid current could be monitored by a meter on the receiver panel. The UHF radio transmitter was a commercial type operating in the range 910 to $960 \mathrm{Mc}$. The UHF transmitter antenna and reflector are shown in figure 8 , and the receiving antenna cable to $R_{1}$ (and $\vec{R}_{2}$ ) can be seen on the ground to the right in the photograph.

The unit shown in figure 8 was manually operated and required an attendant at all times during which the phase-velocity measurements were made, hence the presence of the wind and sun shelter shown in the figure.

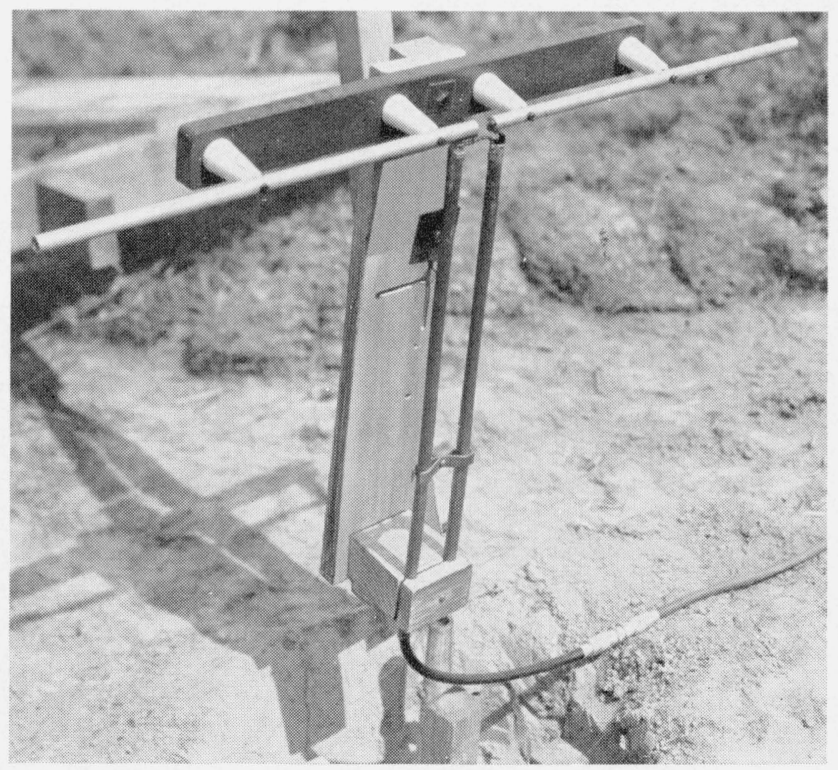

FIgUR: 7. Half-wave center-fed balanced receiving antennu. 
Figure 9 is a front view of radio transmitter $T_{1}$ (and $T_{2}$ ). These units, each of which was housed in an army-type truck, consisted of a 50-w radio transmitter and a 250-w power amplifier, covering the frequency range 148 to $174 \mathrm{Mc}$. The oscillator in the 50-w transmitter was modified with a vernier-

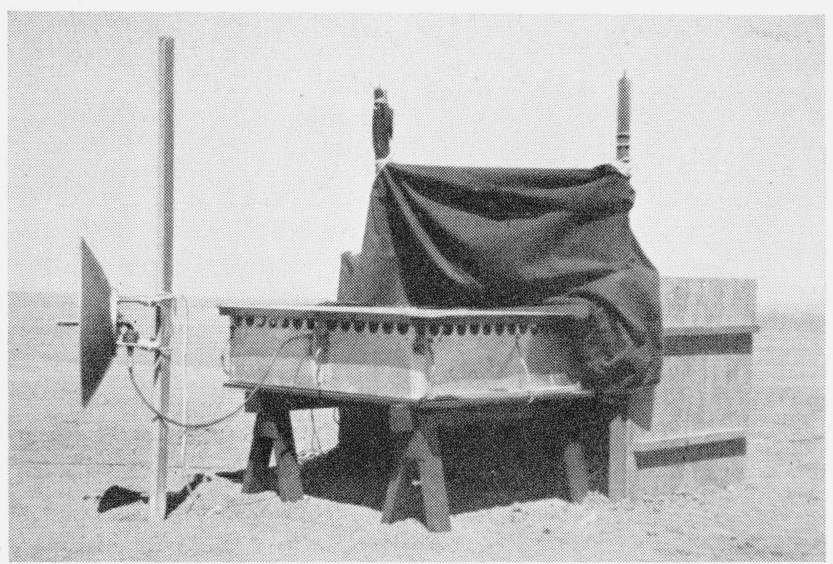

Figure 8. Very-high-frequency radic receiver-ultra-highfrequency radio transmitter station.

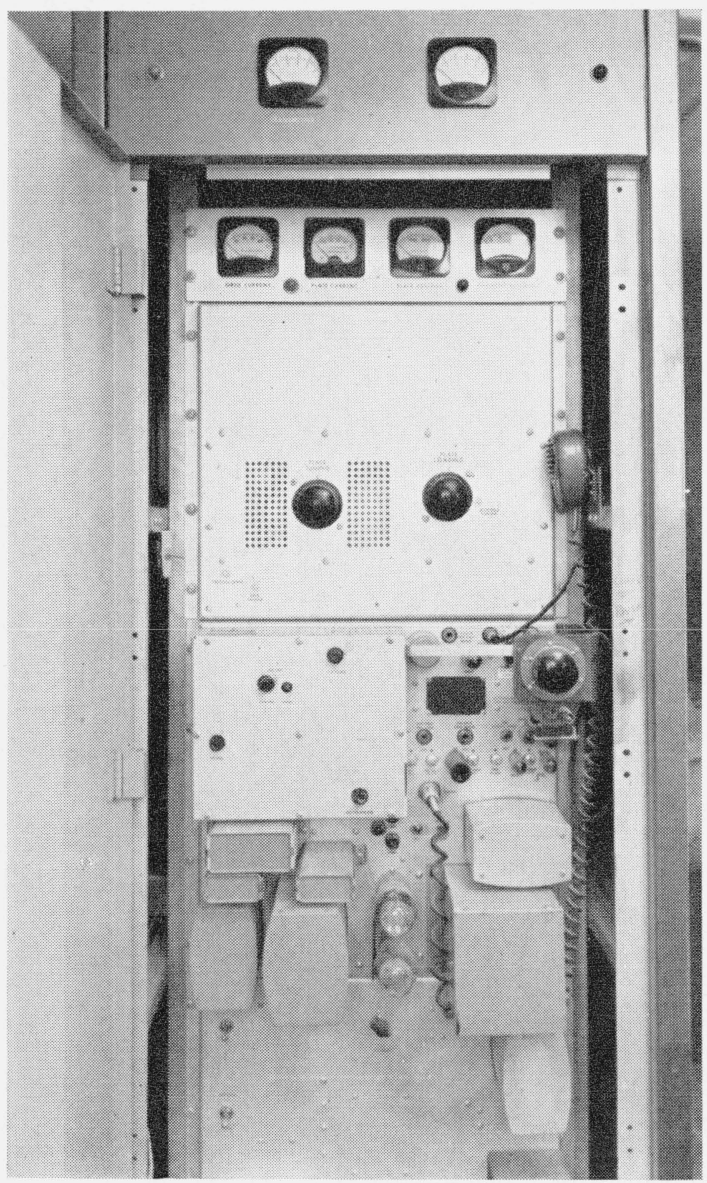

Figure 9. Radio transmitter $T_{1}\left(T_{2}\right)$. frequency control so that the frequency of the transmitter output could be controlled by the knob shown in the right center, over a range of $\pm 5 \mathrm{kc}$ and could easily be set to within $\pm 1 \mathrm{cps}$.

To provide mobility for the $T_{1}$ and $T_{2}$ units, a $5-\mathrm{kw}$ gasoline-engine power unit was mounted on each of the trucks.

Figure 10 is a view of one of the five-element Yagi antennas used to radiate the signals from the $T_{1}$ and $T_{2}$ transmitters, mounted on the rear of the trucks that housed these transmitters. For some of the phase measurements, this same antenna was mounted on the end of an $8-\mathrm{ft}$ boom in order to increase the spacing between the rear of the antenna and the truck.

Figure 11 is a view of the "control" truck that housed radio transmitter $T_{0}$, the two $\mathrm{UHF}$ radio receivers, phase-measuring equipment, and fre-

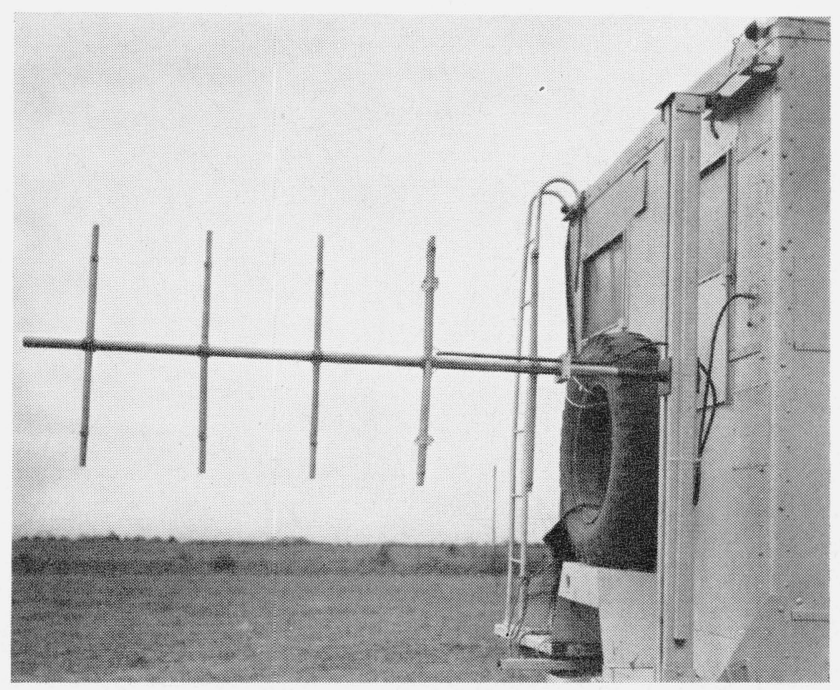

Figure 10. Five element Yagi antenna used at $T_{1}$ and $T_{2}$ transmitters.

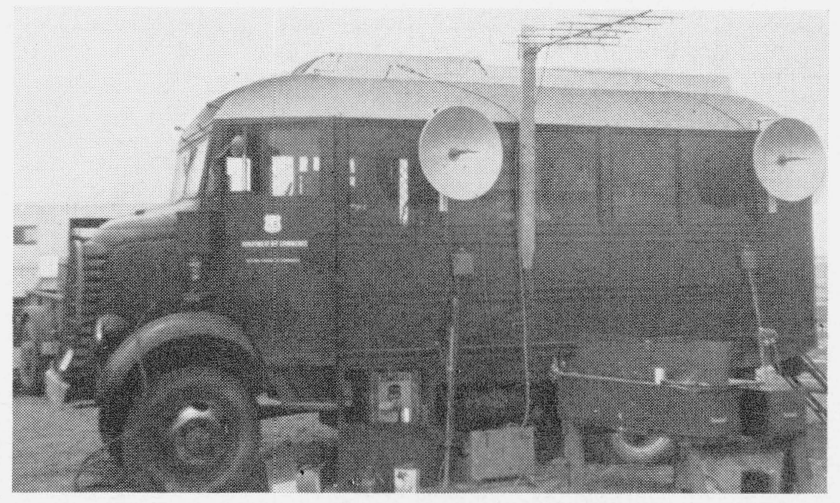

Figure 11. Exterior view of control truck housing phase measuring, frequency-monitoring equipment, and radio transmitter $T_{0}$. 
quency-monitoring equipment shown in block form in figures 4 and 5 . This view shows both types of antennas used with radio transmitter $T_{0}$ : the quarterwave vertical roof antenna and the five-element Yagi antenna, which could be used for either vertical or horizontal polarization. The UHF receiving antenna-reflector assemblies were positioned so as to point toward the transmitting antennas shown in figure 8 .

Figure 12 shows a panel view of the equipment in the control truck. Taken in order from left to right and top to bottom, the main components of each rack are:

1. UHF radio receivers and heterodyne-frequency signal-level meters.

2. phase-monitor scope, RC phase shifter, and communication receivers.

3. electronic phase meter, manual phase shifter, and recorders.

4. frequency-monitor oscilloscope, audiofrequency signal generator, and radio transmitter $T_{0}$.

5. audiofrequency meter, radio receiver, $100-\mathrm{kc}$ frequency standard, and frequency divider.

The meterological equipment consisted of a hygrothermograph, barograph, and an indicating barometer, all housed in a standard type of instrument shelter provided by the Weather Bureau. A sling psychrometer was used to calibrate the hygrothermograph twice each day.

To facilitate operation of the system, two-way communication was provided from the control truck to each of the other four manually operated stations.

Boulder, Colo., June 7, 1954.

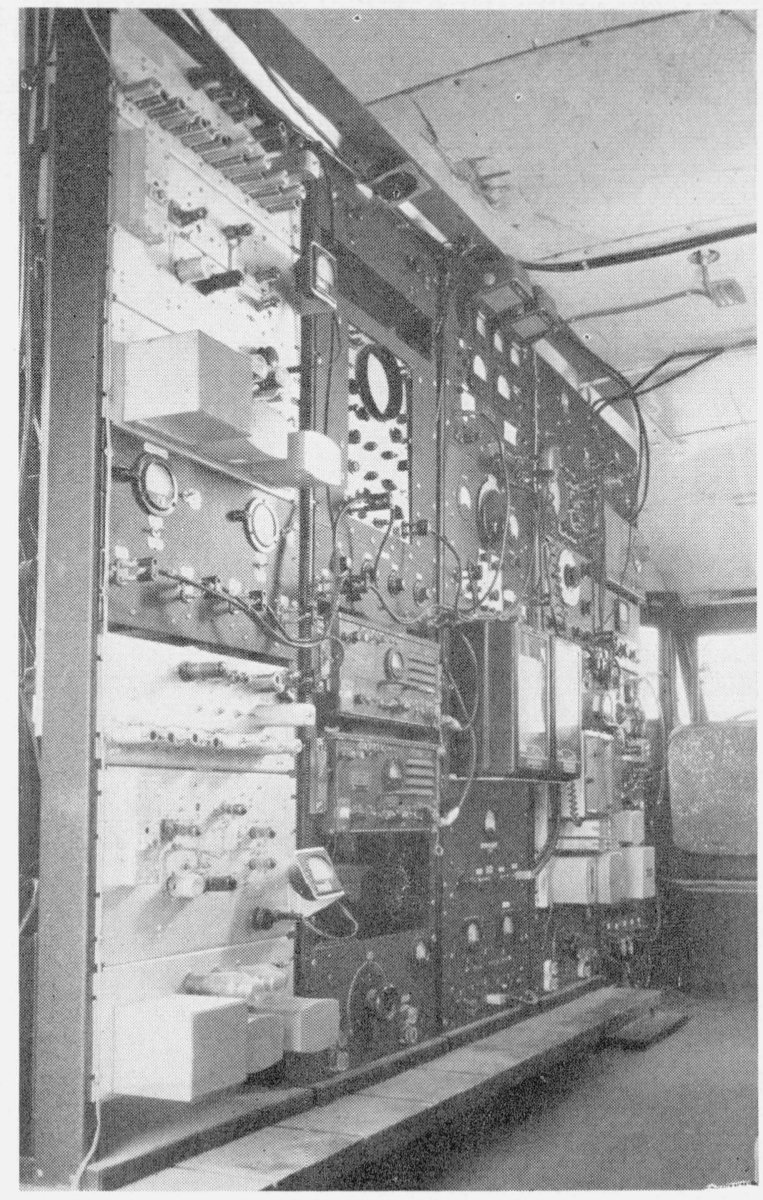

Figcre 12. Panel view of equipment in the control truck. 